\title{
The Enlightenment of Practical Experience of Dust Explosion Protection in Developed Countries to China
}

\author{
Yajing $\mathrm{Bi}^{1, \mathrm{a}, \star}$, Qian $\mathrm{Hou}^{2, \mathrm{~b}}$, Huajun Zhang ${ }^{1, \mathrm{c}}$ \\ ${ }^{1}$ China Academy of Safety Science and Technology, China \\ ${ }^{2}$ Ministry of Emergency Management of the People's Republic of China, China \\ ayajingbi@163.com \\ b jessican@126.com \\ czhj1976_cn@sina.com
}

Keywords: developed countries, dust explosion prevention, experience, inspiration

\begin{abstract}
Measures and suggestions are brought forward for China to with respect to dust explosion prevention, with successful experience and measures adopted by developed countries regarding dust explosion prevention summarized and analyzed in a penetrating way and with the practical situations of safety production in China taken into consideration.
\end{abstract}

\section{Introduction}

On Aug. 2, 2014, an extraordinarily serious aluminum dust explosion accident burst out with Kunshan Zhongrong Metal Products Co., Ltd., a wholly Taiwan-owned enterprise based in Kunshan Economic \& Technological Development Zone, Kunshan, Suzhou, Jiangsu, which caused 146 dead and 114 injured, incurring a direct economic loss of CNY351 million. In recent several years, the vulnerable safety production basis in dust explosion prevention field, weak legal consciousness of enterprises, poor technology equipment \& process, insufficient professional management personnel, unsound dust explosion prevention standard system and relatively lagging fundamental research and industrialization of explosion-proof facilities, in addition to the economic downward pressure which may give rise to reduced input on safety aspect, all bring negative influence on dust explosion prevention and safety production. As a result dust explosion accidents burst out frequently in China. Making use of the practice experience regarding dust explosion prevention in developed countries and considering the practical situations in this regard in China is of high significance to elevating the regulation effect of dust explosion prevention in China.

\section{International Dust Explosion Prevention Attention Review, Ability and Information Share}

2.1 Combustible Dust National Emphasis Program (NEP) in USA. Occupational Safety and Health Administration (OSHA) issued the Combustible Dust National Emphasis Program (NEP), with the main contents including:

(1) Inspection: at least four times of inspections on key enterprises annually

(2) Site Special Target Inspection: Follow-up inspections will be conducted on key enterprises which are found with quite a lot of problems during the inspection. Since the said program was carried out, over 2,600 times of inspections had been conducted as of 2011, with 12,000 incidents of 
non-compliance with regulations, including 8500 times of serious ones. The total amount of diverse fines on these incidents has exceeded USD20 million.

(3) Seminars: The training center of Occupational Safety and Health Administration (OSHA) hosts seminars for Federal and State Ombudsman, business owners, employees, new practitioners and explosion-proof facilities producers and traders, share knowledge and information of dust explosion prevention, etc.

(4) Training: including engineering technology measures and methods for combustion prevention and explosion accidents, dust combustion and explosion standard formulated by National Fire Protection Association, awareness of combustible dust disaster, inspection key points and individual protection training, etc.

(5) Publicity: Establishing special websites and making advertising videos and posters regarding combustible dust security precaution, etc.

2.2 Construction of Dust Parameter Database in Germany. Federal Institute for Material Research compiled the online database of dust parameter in 2012, through which the minimum energy value, initiation temperature, inflammation minimum critical value, explosion pressure and other parameter of diverse dusts could be found when the dusts ignite with diverse conditions undetermined. By making use of this database, the security assessment organization and accident investigation organization can promptly analyze the crucial process of dust ignition and explosion.

When the safety inspection is carried out, not only is the general property of the dust taken into consideration, but also such specific conditions as size of specific dust, surface characteristic of object to which the dust is adhered, dust temperature, etc. should be inspected. Therefore, the inspectors need sampling on the spot of the enterprise and then make overall analysis and assessment. Germany also emphasizes that an enterprise shall in advance engage qualified safety assessors to conduct overall safety assessment on the spot when the enterprise plans new factories and arranges new production facilities and in other layout stages. Where the dust inevitably occurs, the production space should be partitioned. Additionally, Germany also encourages adopting modern technologies such as digit simulation, etc. to conduct safety production assessment on dust hidden danger in a scientific, high-efficiency and low-cost manner [1].

\section{Construction of International Dust Explosion Prevention Standard System}

Thanks to the strict standard system and explosion-proof national standard, factories in some developed countries in Europe and America encounter accidents in a low rate. Since 1990s, European Committee for Standardization has established series dust explosion research projects and organized the European countries to conduct researches, including large-sized explosion test for the combination of window and pipeline, which is taken as the research foundation for amending explosion-proof standards in order to establish European standards [2].

In order to prevent dust explosion, related countries and regions have established dust explosion prevention standard systems which chiefly provide specific designs and precaution technology requirements with respect to dust inerting, explosion initiating, pressure venting, explosion suppresion, flameproof, etc. Thereof, dust explosion parameter is the basis for dust explosion prevention design. Presently, the three mature international standard systems include series standards regarding dust explosion prevention formulated by Association of German Engineers (Verein Deutscher Ingenieure in German, VDI), standard system formulated by National Fire Protection Association and EU dust explosion prevention standard system.

3.1 VDI Dust Explosion Prevention Standard System. VDI standard system is complete in contents, consisting of dust ignition blast dangerousness parameter testing method standards, 
explosion-proof technology standard and explosion-proof product standard, etc. Thereinto, the dust explosion-proof technology standards include such series standards as pressure venting, inerting, pressure resistance, explosion suppresion, etc., with the contents regarding explosion dangerousness analysis, assessment method and precaution technology measures; dust explosion-proof product standards bring forward the ignition- and explosion-proof requirements, testing and validation methods for key equipment, with living example explanations attached which are more visualized and operable [3].

\subsection{Explosion Prevention Standard System formulated by National Fire Protection} Association (NFPA). Explosion prevention standard system formulated by National Fire Protection Association mainly consists of general-use standards such as Code for Pressure Venting of Dust Explosion and NFPA69 Explosion Protection System, etc., covering requirements on ventilation and explosion-proof technology for combustible gas, vapor and combustible dust, and simultaneously bringing forward specific explosion prevention rules and related technology requirements for special combustible dust and industrial explosion prevention[4]. The explosion prevention standard system formulated by National Fire Protection Association mainly consists of the following:

(1) General-use explosion-proof standards with NFPA69 taking the dominant position. Such standards mainly bring forward explosion protection technology requirements such as explosion suppresion, flameproof and pressure resistance design, etc. for combustible and explosive substances, including combustible gas, vapor, mist and dust and the mixture thereof, and make rules for technology requirements on passive explosion-proof product and installation, supervision and maintenance of explosion-proof system.

(2) Explosion-proof technology rules or guidelines with FPA68 taking the dominant position. Such rules or guidelines bring forward requirements on ventilation for combustible gas, design, location and installation of combustible gas, mist and combustible dust or mixture explosion pressure venting system, and system supervision and maintenance. NFPA77 Recommended Practice on Static Electricity, NFPA99 Standard for Exhaust Systems for Air Conveying of Vapors, Gases, Mists and Noncombustible Particulate Solids, etc. are also the general-use technology norms in allusion to explosion-proof technology.

(3) Some industries also have established specific rules of explosion prevention measures. These industries mainly comprise agriculture, food, wood processing, boiler system, production, processing and disposal of combustible particulate solids.

(4) Specialized explosion-proof technology requirements for special products.

For instance, NFPA484 Standard for Combustible Metals, Metal Powders and Metal Dusts and NFPA655 Sulphur Fire Blast Precaution etc. establish specialized explosion-proof technology requirements for sensitive products.

In general, NFPA explosion prevention standard system emphasizes the comprehensive explosion-proof technology requirements of explosion environment and establishes explosion-proof standards and technology rules in diverse aspects such as industries, products, etc.

3.3 EU Dust Explosion Prevention Standard System. EU dust explosion prevention standards comprise two categories, namely, explosion-proof technologies and explosion-proof products, which govern mixture of combustible dust and air, mixture of gas (vapor) and air, mixture of combustible dust, gas (vapor) and air. Thereinto, most of the explosion-proof standards do not distinguish combustible gas from combustible dust.

The EU dust explosion prevention standard system features the following: 
(1) The dust explosion prevention standard system is relatively complete. Through quite long-standing development, the dust explosion prevention standards of major developed countries have covered in diverse aspects the whole process from raw material to product, from industries to employees and from production to supervision. Strict requirements have been roughly carried out in diverse production links, with the execution and supervision of standards intensified.

(2) The dangerousness testing standard regarding dust explosion are roughly consistent with the parameters, which mainly comprise lower explosive limit, oxygen concentration limitation, minimum ignition energy, ignition temperature, etc. The researches on influence rule of factors such as explosive environment pressure and temperature have been always the hot spots. To establish authoritative and shared combustible dust explosion parameter database is necessary and fundamental.

(3) Execution Efficiency and Effect Emphasized Some standards in foreign countries and regions uniformly regulate combustible gases and combustible dusts and bring forward specialized explosion-proof technology combination measures for different industries or products. Such largely intensifies the execution efficiency and effect of standards and rules.

\section{Inspiration and Suggestion}

4.1 Further Complete Our Dust Explosion Prevention Standard System. Thus far, China has roughly established dust explosion prevention and protection national standard system [5]. However, as compared with the foreign standards like standards formulated by National Fire Protection Association, some standards of same categories of China features low operability. For instance, there are only a few articles in the GB15777 Safety Regulations for Dust Explosion Prevention and Protection. To metal polishing dust explosion prevention, the American NFPA484 Standards for Combustible Metals could completely cover all the situations, while our GB17269 Safety Regulation for The Prevention and Protection of Dust Explosion in Manufacturing Powder of Aluminum and/or Magnesium is chiefly formulated for production of aluminum and/or magnesium powders, but does not cover explosion prevention and protection thereof.

4.2 Intensify the Production and R\&D of Dust Explosion-Proof Facilities and Equipment. In recent years, some European and American countries have continuously updated the dust explosion-proof equipment and facilities and consecutively launched the equipment used in dust explosion site of blast furnace blowing combustion, dust explosion prevention facilities used in feed processing, dust explosion prevention facilities used in coal powder production, etc[6]. However, over $80 \%$ dust explosion accident sites in China lack dust explosion prevention and protection measures. Some large-sized processing enterprises with high risk in China have adopted efficient dust explosion prevention measures, but the major explosion prevention equipment is chiefly imported, dust explosion prevention equipment manufacturing sector has not been industrialized. Domestic dust explosion-proof equipment manufacturing has not yet formed an industry. It requires the production and research and development of dust explosion-proof devices and equipment to form an industry and be equipped with related industries and enterprises.

4.3 Establish Dust Explosion Prevention Parameter Database. To evaluate the industrial dust date of such major industries as sugar manufacturing, metal, coal, plastic, etc. in China, so that the production and managerial personnel of enterprises and governmental departments could conveniently and promptly check the minimum energy value, ignition temperature, inflammation minimum critical value, pressure arising from explosion, and other parameters of diverse dusts when various conditions are undetermined. In addition, the safety assessment organizations and accident investigation organizations could also make use of the said database to analyze the key 
process of dust ignition and explosion.

4.4 Reinforce Precaution and Publicity. The prevention and protection of dust explosion focuses on precaution. When the complete basic standards of explosion prevention and control categories are established, explosion prevention production equipment, and explosion venting, suppresion and inhibition products which are essentially safe also need to be developed. The uppermost point in explosion prevention stands at combustion source control. Dangerous combustion source should be avoided from the equipment being used in manufacturing process to the maximum extent, which ensures the production equipment essentially safe. Therefore, regular and continual safety production education and publicity activities should be carried out within the whole society to ensure safety by keeping ringing the alarm bell.

\section{Conclusion}

Using for reference related dust explosion prevention technologies, laws and regulations and supervision methods of developed countries, probing the dust explosion prevention standards and technology applications, and sharing the efficient measures regarding dust explosion precaution are very important to help elevate the dust explosion prevention level of China.

\section{Acknowledgment}

This work is supported by National Key R\&D Program of China (No.2017YFC0805100, 2016YFC0801305) and basic scientific research project founded by China Academy of Safety Science and Technology(No.2017JBKY07, 2018JBKY04). All funding supports are gratefully acknowledged.

\section{References:}

[1] Zhi Wang, Qianqian Wang. Development of Domestic and Foreign Dust Explosion Prevention Safety System [J]. Labor Protection, 2017, (09):14-17.

[2] Youbang Dong, Xiaoyu Wu. Development Status and Countermeasures of Dust Explosion Prevention Safety Standards [J]. Security, 2014(11):36-38.

[3] Haizhou Zhang, Man Lu, Qian Li. Current Situation of Dust Explosion Prevention of Grain Sector and Thinking Thereof [J]. Grain Science and Technology and Economy, 2016(06):56-57.

[4] Qian Li. Issues to be Concerned in Dust Explosion Prevention of Grain Depot [J]. Grain \& Oil Storage Science \& Technology Communications, 2015(02):28-30.

[5] Shengjun Zhong. Problems and Suggestions on Dust Explosion Prevention and Protection in China [J]. Labor Protection, 2016(09):14-16.

[6] Xueyong Li. Innovation and Practice of Dust Comprehensive Prevention and Control Technology in Shandong Coal Mine[J]. Journal of Safety Science and Technology, 2014,(S1):270-275. 